\title{
The Effect of Milankovitch Variations in Insolation on Equatorial Seasonality
}

\author{
YOSEF ASHKENAZY \\ Department of Solar Energy and Environmental Physics, The Jacob Blaustein Institutes for Desert Research, \\ Ben-Gurion University of the Negev, Midreshet Ben-Gurion, Israel \\ IAN EISENMAN \\ Division of Geological and Planetary Sciences, California Institute of Technology, Pasadena, California, \\ and Department of Atmospheric Sciences, University of Washington, Seattle, Washington
}

HEZI GILDOR

The Fredy and Nadine Herrmann Institute of Earth Sciences, Hebrew University of Jerusalem, Jerusalem, Israel

\section{ELI TZIPERMAN}

Department of Earth and Planetary Sciences, and School of Engineering and Applied Sciences, Harvard University, Cambridge, Massachusetts

(Manuscript received 1 March 2010, in final form 26 July 2010)

\begin{abstract}
Although the sun crosses the equator 2 times per year at the equinoxes, at times in the past the equatorial insolation has had only one maximum and one minimum throughout the seasonal cycle because of Milankovitch orbital variations. Here a state-of-the-art coupled atmosphere-ocean general circulation model is used to study the effect of such insolation forcing on equatorial surface properties, including air and sea temperature, salinity, winds, and currents. It is shown that the equatorial seasonality is altered according to the insolation with, for example, either maximum sea surface temperature (SST) close to the vernal equinox and minimum SST close to the autumnal equinox or vice versa. The results may have important implications for understanding tropical climate as well as for the interpretation of proxy data collected from equatorial regions.
\end{abstract}

\section{Introduction}

The global and annual mean insolation changes only moderately in response to changes in Earth's orbit, but the associated geographic and seasonal redistribution of solar radiation on Earth may dramatically affect Earth's climate (Milankovitch 1941; Berger 1978; Laskar 1990; Laskar et al. 1993; Paillard 2001). The Milankovitch hypothesis (Milankovitch 1941), which links changes in summer insolation at the high latitudes of the Northern Hemisphere to the glacial-interglacial oscillations, is probably the most widely known example.

Corresponding author address: Yosef Ashkenazy, Department of Solar Energy and Environmental Physics, BIDR, Ben-Gurion University of the Negev, 84990 Midreshet Ben-Gurion, Israel. E-mail: ashkena@bgu.ac.il
Whereas the solar radiation in extratropical regions peaks around the solstices, the solar radiation in equatorial regions tends to have maxima close to the equinoxes, when the sun crosses the equator two times per year. As a result, some equatorial regions, such as the western Pacific Ocean warm pool, do not have a welldefined seasonal cycle (Köberle and Philander 1994). Other regions, such as the eastern equatorial Pacific (Horel 1982; Philander et al. 1987; Köberle and Philander 1994; Li and Philander 1996; Gu et al. 1997) and Atlantic Ocean (Horel 1982; Li and Philander 1997) have a welldefined seasonal cycle, which has been suggested to be a result of ocean-atmosphere interaction and the asymmetry of the continents around the equator (Philander et al. 1996; Li and Philander 1996, 1997).

Earth's insolation is affected by the slowly varying orbital parameters of eccentricity, obliquity, and precession 



FIG. 1. (left) Insolation and (right) zonal-mean SST for (top) present day, (middle) 201, and (bottom) $213 \mathrm{kyr}$ BP as a function of month. Note the nearly opposite seasonality in insolation and SST for the 201 and 213 kyr BP cases.

(Milankovitch 1941; Berger 1978; Laskar et al. 1993; Paillard 2001). These have approximate time scales of 400 and 100, 40, and $20 \mathrm{kyr}$, respectively. The eccentricity parameter indicates changes of the orbit of Earth around the sun, which varies between more elliptical and more circular shapes. The obliquity parameter reflects changes in the tilt of the axis of rotation relative to the normal to the plane of rotation. The precession parameter indicates the net effect of the precession of Earth's rotation axis and the precession of its orbit around the sun. It has been shown that the maximum and minimum equatorial insolation vary with the time scale of the eccentricity parameter and one-half of the time scale of the precession parameter (Berger et al. 2006; Ashkenazy and Gildor 2008). The nontrivial observation of interest here is that the combined effect of the three orbital parameters can lead to situations in which Earth is far enough from the sun during the equinox, when the sun is situated above the equator, that the equatorial insolation is not maximal then.

Previous studies (Short et al. 1991; Crowley et al. 1992) have forced a two-dimensional energy balance model with insolation forcing varied to represent the past $800 \mathrm{kyr}$. It was found that tropical regions may have considerable changes in the seasonal cycle as a result of the different insolation forcing (see Fig. 14 of Short et al. 1991).

The goal of the study presented here is to show that such variations of the seasonal cycle of equatorial insolation significantly change the seasonality in sea surface temperature (SST), as well as of other oceanic and atmospheric fields near the equator. Specifically, we find that, depending on the insolation forcing, January may either be significantly colder or warmer than June, throughout the equatorial domain. This has implications in several different research areas. First, it puts in perspective our understanding of the present-day seasonal cycle at the equator itself, as studied in the abovementioned papers by Philander and coworkers. Second, the difference in seasonality in equatorial SST relative to the extratropics, for which seasonality is more robust, may require different calibration and interpretation of proxy records acquired from the tropical region. Last, tropical climate variability due to El Niño-Southern Oscillations (ENSO) may be very sensitive to the equatorial seasonal cycle (e.g., Tziperman et al. 1994, 1998, 

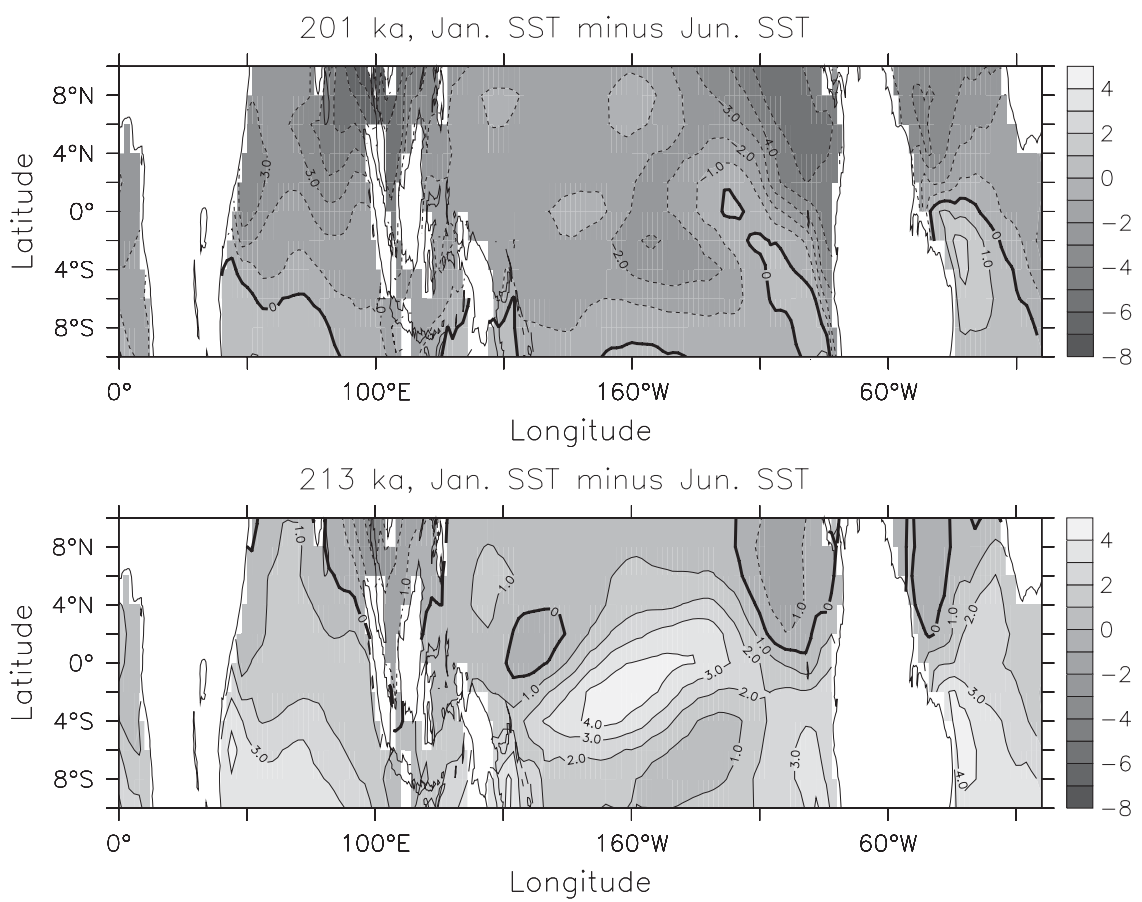

FIG. 2. (top) January SST minus June SST for the $201 \mathrm{kyr}$ BP case. (bottom) As in (top), but for the $213 \mathrm{kyr}$ BP case. The values for the $201 \mathrm{kyr} \mathrm{BP}$ case are negative nearly everywhere, whereas those for the $213 \mathrm{kyr}$ BP case are nearly everywhere positive, indicating that the seasonal cycles for the two cases are approximately opposite. The heavy solid line indicates the 0 -value contour line.

1997), which has direct implications for past ENSO variability as well as the interpretation of proxy records from the equatorial Pacific.

Below we show results of a fully coupled atmosphereocean general circulation model (GCM), the National Center for Atmospheric Research (NCAR) Community Climate System Model, version 3.1 (CCSM3.1; Collins et al. 2006). We run the model under two different insolation forcings: one with maximum equatorial insolation close to the vernal equinox and minimum close to the autumnal equinox, and the other with minimum insolation close to the vernal equinox and maximum close to the autumnal equinox. These two cases lead to very different seasonal cycles at the equator and enable us to draw conclusions about the effect of the seasonality in insolation on the equatorial seasonality of the climate system. We note that the response of the tropics to Milankovitch forcing was also investigated, in a different context, by Clement et al. (1999) and Cane (1998).

\section{Model and simulations}

The NCAR CCSM3.1 is a fully coupled climate model composed of atmospheric and oceanic GCMs, a land model, and a sea ice model. We run the model in its standard resolution. The atmosphere has T42 spectral truncation (approximately $3^{\circ}$ ) with 26 vertical levels. The oceanic model has a spatial resolution of about $1^{\circ}$ and 40 vertical levels. This configuration has been used extensively to model past, present, and future climates (e.g., Otto-Bliesner et al. 2006; Collins et al. 2006; Meehl et al. 2006).

We consider three runs that have differing insolation forcing but have initial conditions and other forcings equivalent to present day. We examine insolation forcings corresponding to present day, $201 \mathrm{kyr}$ before present (BP), and $213 \mathrm{kyr}$ BP. Whereas the present-day equatorial insolation peaks at both equinoxes (end of March and September), the $201 \mathrm{kyr}$ BP insolation peaks only at the end of March and the 213 kyr BP insolation peaks only at the end of September (Fig. 1). These three cases span the range of possible equatorial insolation seasonalities.

The model was run for $82 \mathrm{yr}$ of simulation, starting from present-day initial conditions, for both the 201 and 213 kyr BP insolation cases. The results shown below are based on the "climatology" calculated from the last 20 of the $82-\mathrm{yr}$ simulations. The present-day climatology is based on years $861-880$ of a CCSM3 control run (Collins et al. 2006). While the global ocean is not 

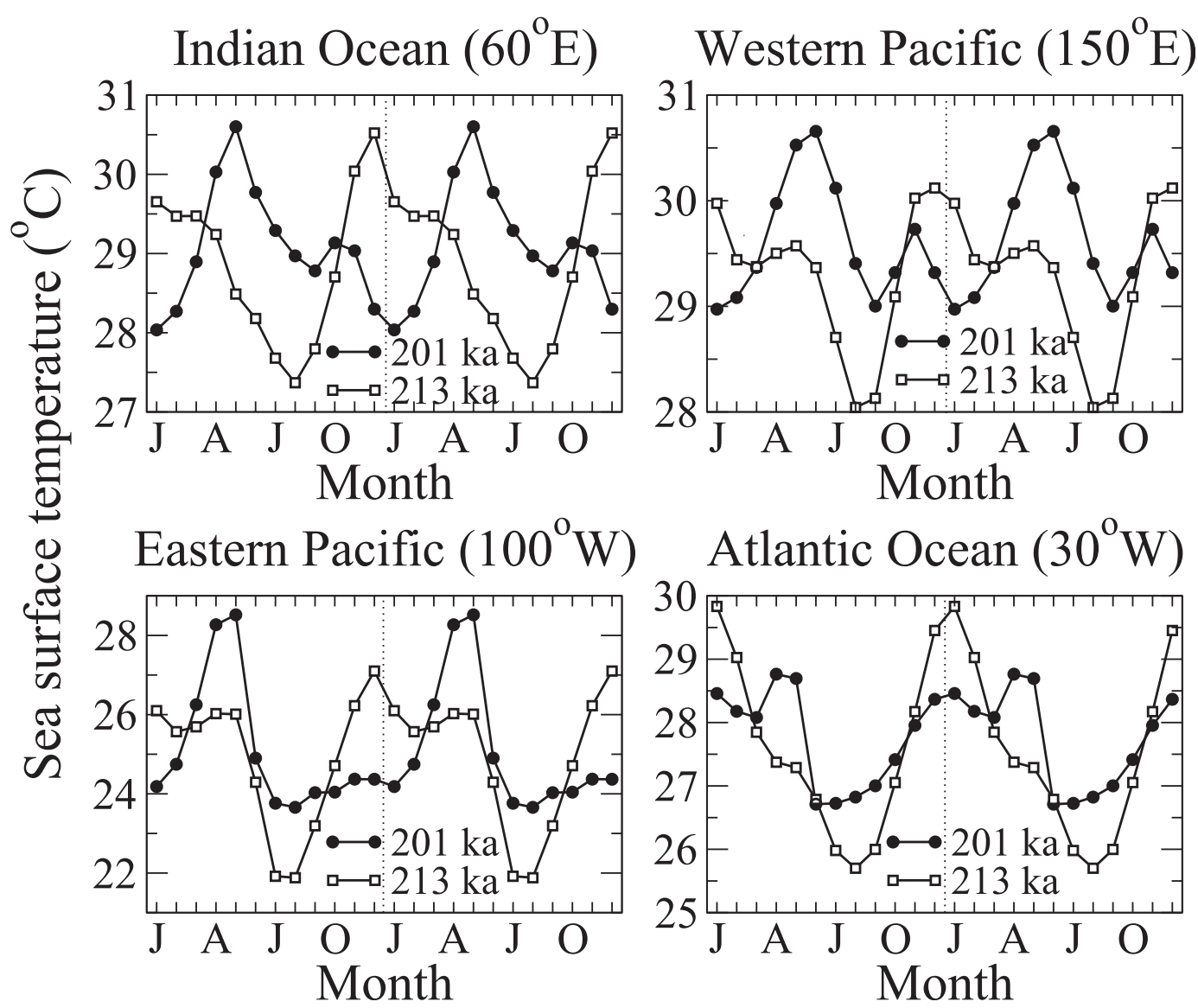

FIG. 3. The seasonal cycle in SST for four locations in the equatorial ocean for the 201 (filled circles) and 213 (open squares) kyr BP cases. Note the different seasonal cycles for the two cases and the biannual seasonality for both cases in most locations.

expected to reach a steady state after $82 \mathrm{yr}$ of simulations, the different insolation forcing scenarios primarily affect the tropical region, where the ocean stratification is strong and where we therefore find that the upper-ocean seasonal cycle seems to largely equilibrate within the integration period.

\section{Results}

The zonal-mean SST at latitudes near the equator is shown in the right column of Fig. 1. The temperature range of the present-day run is smaller than that of 201 or $213 \mathrm{kyr} \mathrm{BP}$. The seasonality is almost opposite for the 201 and $213 \mathrm{kyr}$ BP cases, and the present-day state is closer to the $213 \mathrm{kyr}$ BP state, which is expected to be due to the closer similarity in the insolation forcing. For latitudes farther away from the equator, the seasonality of the three cases becomes increasingly similar.

To demonstrate the spatial pattern of the seasonal variations of the 201 and $213 \mathrm{kyr}$ BP cases, we depict in Fig. 2 the difference in SST between January and June.
These two months represent the approximate times of largest differences in the seasonal cycles of the two cases (see also Fig. 7 below). This difference is negative for the 201 kyr BP case (top panel) in nearly every ocean location between $10^{\circ} \mathrm{S}$ and $10^{\circ} \mathrm{N}$, indicating that the equatorial SST is cooler in January than in June in this latitude band. The bottom panel, however, shows that the SST is warmer in January than in June throughout the equatorial region for the $213 \mathrm{kyr}$ BP insolation case. This dramatically different and opposite SST seasonality is especially expressed in the central Pacific Ocean.

Previous studies examining the seasonal cycle in specific regions of the equatorial ocean (e.g., Mitchell and Wallace 1992; Nigam and Chao 1996; Chang 1996; Li and Philander 1996, 1997) have proposed a variety of mechanisms to explain the differing seasonal cycles. It is thus interesting to study zonal differences in the equatorial seasonal cycle in the simulations presented here. In Fig. 3, we plot the SST seasonal cycle in the Indian $\left(60^{\circ} \mathrm{E}\right)$, western Pacific $\left(150^{\circ} \mathrm{E}\right)$, eastern Pacific $\left(100^{\circ} \mathrm{W}\right)$, and Atlantic $\left(30^{\circ} \mathrm{W}\right)$ Oceans. It is clear that the seasonality 

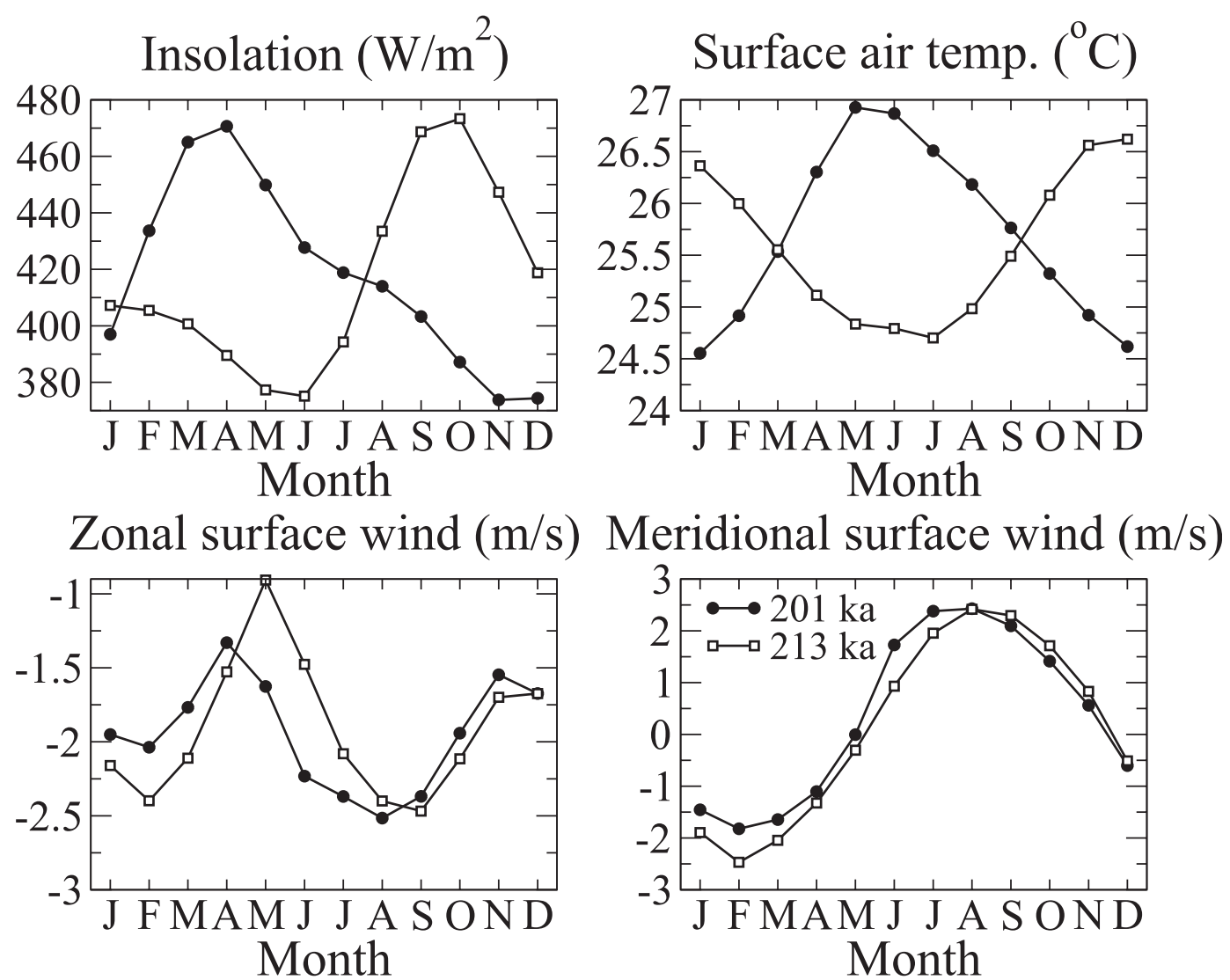

FIG. 4. Zonal-mean seasonal cycle, averaged over $4^{\circ} \mathrm{S}-4^{\circ} \mathrm{N}$, in (top left) equatorial insolation, (top right) surface air temperature, (bottom left) surface zonal wind, and (bottom right) surface meridional wind. Values for 201 (filled circles) and 213 (open squares) kyr BP are indicated. Whereas the insolation and surface air temperature exhibit strikingly different seasonal cycles, the zonal and meridional winds are only slightly affected by the insolation changes.

of the 201 and 213 kyr BP simulations are very different, suggesting that the insolation forcing plays a primary role in determining equatorial seasonality. Despite the single minimum and maximum in insolation for the 201 and 213 kyr BP cases (Fig. 1), a biannual cycle is visible in all locations for the $201 \mathrm{kyr} \mathrm{BP}$ case and for the western and eastern Pacific for the $213 \mathrm{kyr}$ BP case (Fig. 3). Thus, ocean-atmosphere equatorial processes (e.g., Mitchell and Wallace 1992; Nigam and Chao 1996; Chang 1996; Li and Philander 1996, 1997) may still play an important role in determining this biannual seasonality. Interestingly, the zonal-mean SST (Figs. 1, 4) has only one minimum and maximum in the annual cycle.

Atmospheric fields are also expected to be altered, either directly because of the different seasonality in insolation or indirectly because of air-sea interaction, which is affected, for example, by changes in the seasonality of SST. In Fig. 4 we present the annual cycle (averaged over $4^{\circ} \mathrm{S}-4^{\circ} \mathrm{N}$ ) for the 201 and $213 \mathrm{kyr} \mathrm{BP}$ cases in insolation, surface air temperature, and zonal and meridional winds. While the surface air temperature exhibits almost opposite seasonality for the two cases, with a time lag of 1-2 months behind the insolation, the seasonality of the zonal and meridional wind components remains roughly unchanged. This is surprising, as one might expect the winds to be altered as the SST and surface air temperature change. However, the equatorial surface winds are also linked to the global atmospheric circulation, which does not primarily relate to the equatorial seasonality but rather to the equator-to-pole temperature gradient. The equator-to-pole temperature gradient is more dramatically affected by high-latitude temperatures than by equatorial temperatures, as the changes in high-latitude temperatures are typically much larger than the equatorial ones.

It may be expected that the difference in the seasonality of the SST and of different atmospheric fields, due to the variation in the equatorial insolation seasonality, will affect El Niño variability, as the central Pacific SST is a key factor in this phenomenon. We find, in particular, 

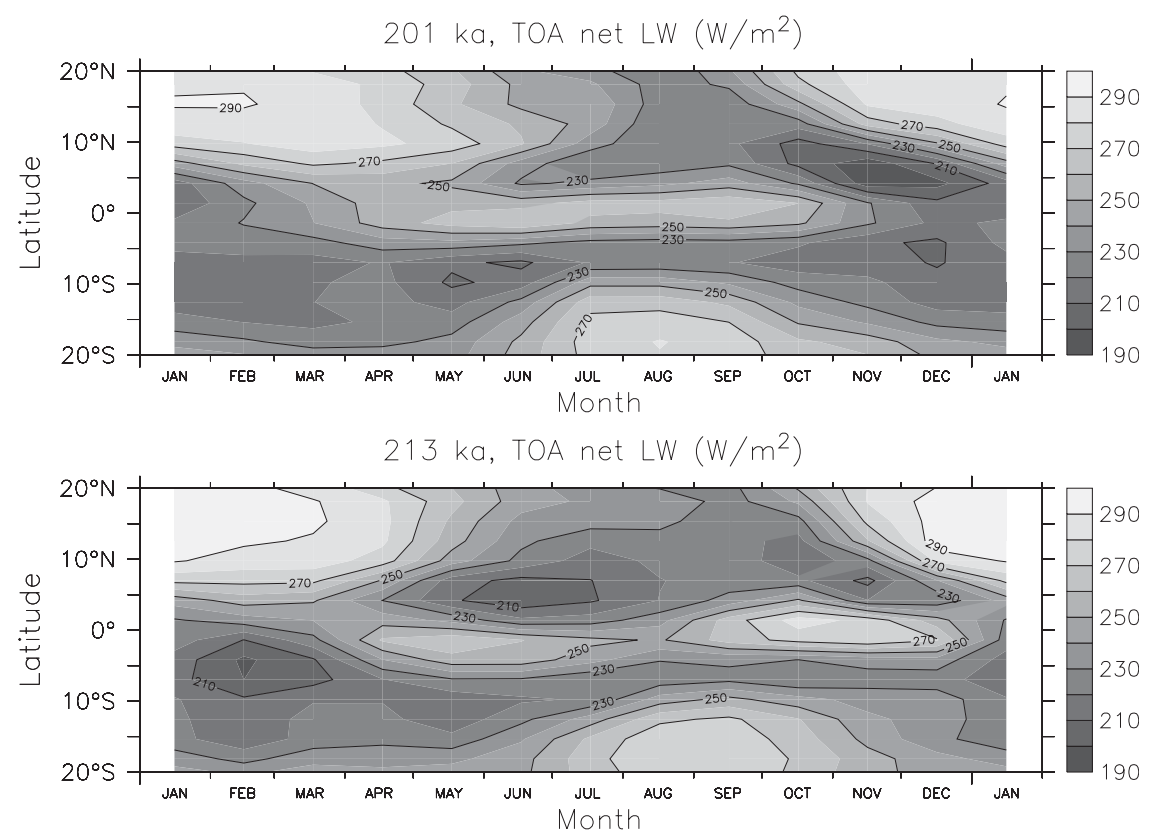

FIG. 5. Latitude-time diagrams of TOA net longwave radiation $\left(\mathrm{W} \mathrm{m}^{-2}\right)$ for the (top) 201 and (bottom) $213 \mathrm{kyr}$ BP runs. The values are the average over $170^{\circ} \mathrm{E}-180^{\circ}$, in the western Pacific. Minimum values indicate the location of the ITCZ.

that the seasonality of the intertropical convergence zone (ITCZ) is very different between the 201 and $213 \mathrm{kyr}$ BP runs considered here. This is demonstrated in Fig. 5, where the net outgoing longwave radiation (OLR) at the top of the atmosphere (TOA) is depicted. Minimum OLR values indicate the location of the ITCZ as high clouds there associated with the ITCZ emit low longwave radiation because of their cold cloud-top temperature. There are also indications that the phase locking of ENSO to the seasonal cycle may be different in these runs, as may be expected (e.g., Tziperman et al. 1994, 1998, 1997). However, our model integrations are not sufficiently long to obtain conclusive results on the effect on ENSO, and the CCSM control simulation of the ITCZ seasonality suffers some biases that make it difficult to rely on its simulation of ITCZ seasonality for different Milankovitch forcing parameters. Still, the clear difference in ITCZ between the two runs suggests that the ITCZ is indeed linked tightly to the insolation forcing; see Sachs et al. (2009) on the topic of changes in the location of the ITCZ during the past several hundred years. More in the way of motivation, we note that changes in seasonality and amplitude of maximum of equatorial SST may also lead to changes in atmospheric teleconnections that may be driven from the tropics, as studied, for example, by Cane (1998), Kukla and Gavin (2004, 2005), and Huybers and Molnar (2007).

Wang and Wang (1999) suggested that the annual cycle of insolation forcing may act as a "symmetry breaker," resulting in the eastern Pacific cold tongue following either the Northern Hemisphere or Southern Hemisphere temperature seasonality. The TOA net longwave radiation presented in Fig. 5 clearly indicates that the insolation forcing has a primary role in determining the location of the ITCZ. Since the ITCZ is linked to the location of the cold tongue, our results support the hypothesis of Wang and Wang (1999).

Previous studies have suggested that the Hadley circulation is linked to the location and intensity of the ITCZ, to the equator-to-pole temperature gradient, and to convection in the tropics (e.g., Held and Hou 1980; Lindzen and Hou 1988; Hou and Lindzen 1992; Schneider 2006; Walker and Schneider 2006). Thus, changes in the ITCZ are expected to trigger changes in the Hadley circulation. We have constructed the streamfunction for the zonally averaged meridional atmospheric circulation for the two runs and find that the annual mean circulation is very similar in the two. The main (small) difference is in the Southern Hemisphere cell, which is larger by $20 \times 10^{9} \mathrm{~kg} \mathrm{~s}^{-1}$ for the $201 \mathrm{kyr} \mathrm{BP}$ run; this is mainly because of the difference in June at which the Southern Hemisphere cell is stronger by about $60 \times$ $10^{9} \mathrm{~kg} \mathrm{~s}^{-1}$. Other than during this month, the circulation is almost identical for the two cases. The Northern Hemisphere/Southern Hemisphere maximum circulation is $\sim 240 \times 10^{9} \mathrm{~kg} \mathrm{~s}^{-1}$. We have also constructed the empirical orthogonal functions of the mean seasonal cycles of the two runs (Fig. 6) and found, similar to Dima 

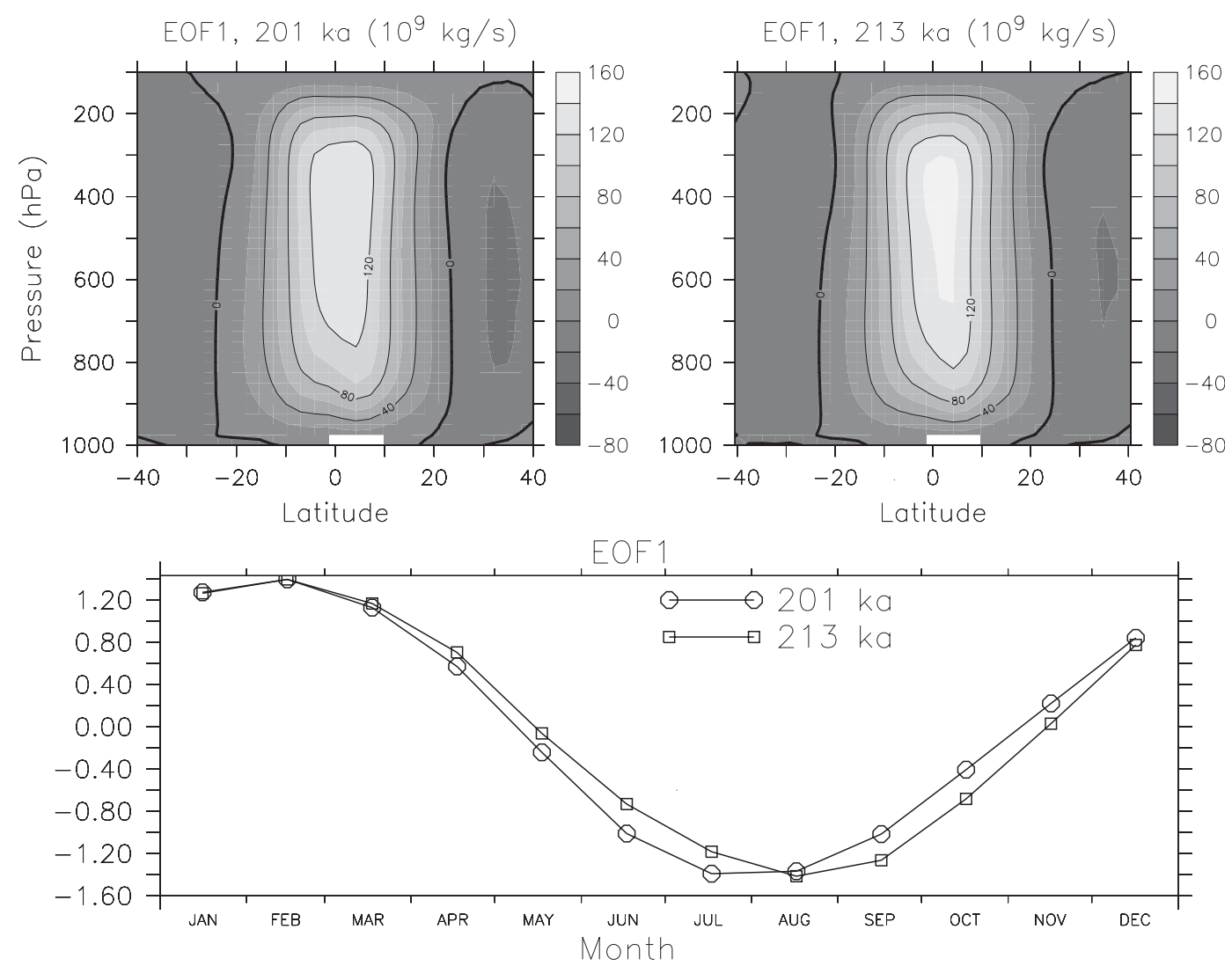

FIG. 6. The first EOF of the (top left) 201 and (top right) $213 \mathrm{kyr}$ BP runs. The two are similar, with a difference of $\sim 20 \times 10^{9} \mathrm{~kg} \mathrm{~s}^{-1}$. (bottom) The time series of the first EOF, which is also similar for the two cases.

and Wallace (2003), that the first EOF accounts for $\sim 95 \%$ of the seasonal variance. The first EOFs of the two runs are similar, with differences of $\sim 20 \times 10^{9} \mathrm{~kg} \mathrm{~s}^{-1}$. The time series associated with the first EOF are also similar, with a minimum value at July (August) for the 201 (213) kyr BP runs (Fig. 6). The relatively small difference in the Hadley circulation for the two runs indicates that even significant changes in tropical seasonality have only a marginal effect on the amplitude and seasonality of the Hadley circulation, suggesting that the equatorto-pole temperature gradient may play a primary role in the seasonal cycle of the Hadley circulation. This seems consistent with the coupled GCM simulations of Otto-Bliesner and Clement (2005), who showed that the Hadley circulation was stronger during the Last Glacial Maximum relative to present day and concluded that the meridional SST gradient seems to be a major control of the Hadley cell amplitude.

For the simulated ocean, in Fig. 7 we present the seasonal cycle (averaged over $4^{\circ} \mathrm{S}-4^{\circ} \mathrm{N}$ ) in SST, sea surface salinity (SSS), and zonal and meridional surface currents. All of these oceanic variables have markedly different seasonal cycles for the 201 and $213 \mathrm{kyr}$ BP cases.
This is in contrast to the surface winds shown in Fig. 4 that were minimally affected by the insolation differences. In the case of surface salinity, not only is the seasonal cycle altered, but the surface salinity for the $213 \mathrm{kyr} \mathrm{BP}$ case is larger than that of the $201 \mathrm{kyr} \mathrm{BP}$ case in all months of the year, suggesting accompanying changes in the hydrological cycle or in ocean circulation.

Another important field for equatorial dynamics is precipitation. In Fig. 8 we present the precipitation seasonality at four different equatorial ocean locations, similar to Fig. 3. The seasonal cycles of the $201 \mathrm{kyr}$ BP case are very different from the $213 \mathrm{kyr}$ BP case. Interestingly, the precipitation differences in these locations (Fig. 8) are not very similar to the SST differences (Fig. 3). The differing seasonal cycles of precipitation and SST suggest that other phenomena that are linked to equatorial dynamics (such as ENSO and monsoons) may be altered as a result of the different insolation forcing.

\section{Discussion and conclusions}

The dynamics determining the precise equatorial SST seasonality is clearly complicated and involves many 

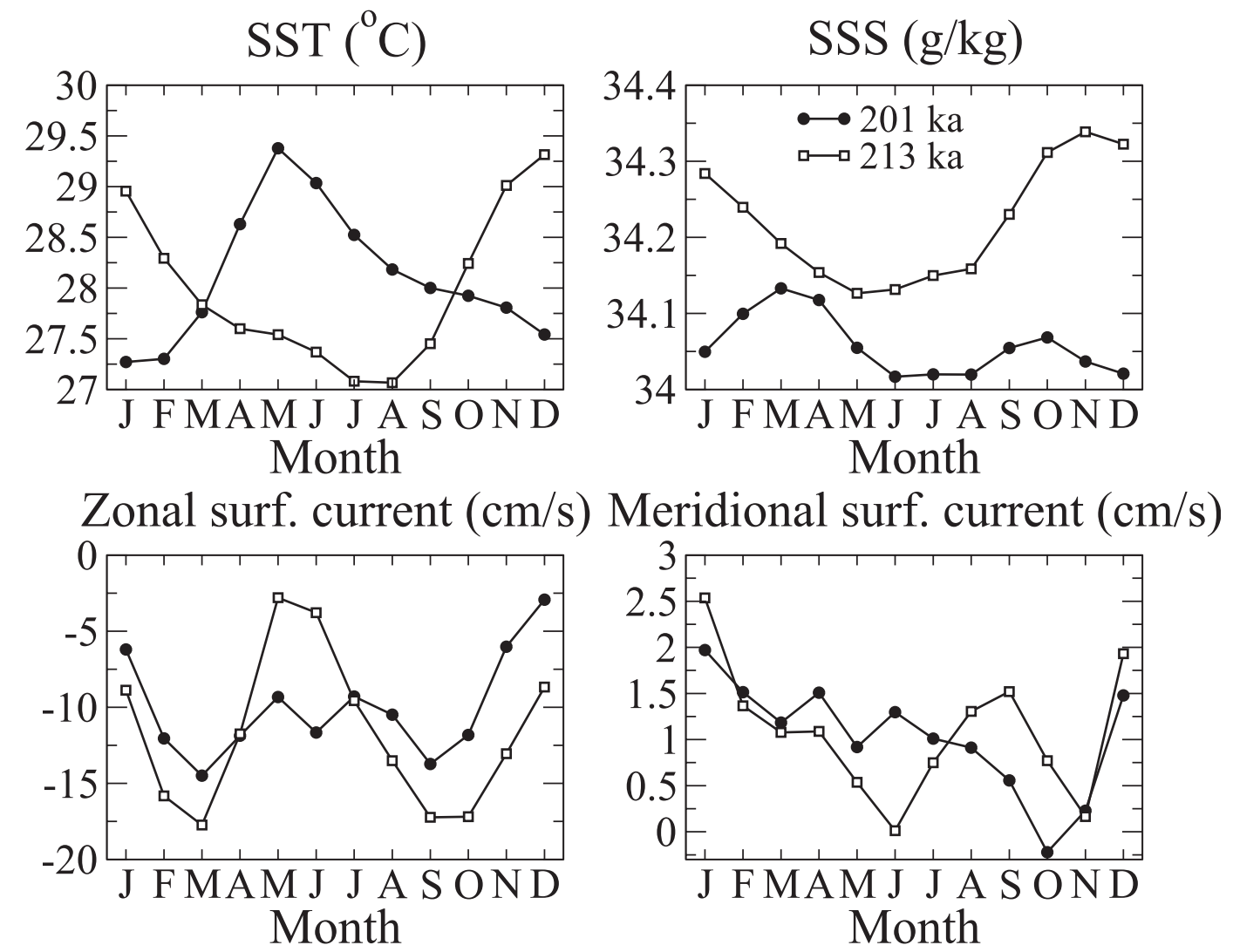

FIG. 7. Zonal-mean seasonal cycle, averaged over $4^{\circ} \mathrm{S}-4^{\circ} \mathrm{N}$, in (top left) SST, (top right) SSS, and (bottom left) zonal and (bottom right) meridional surface currents. Here all fields exhibit considerably different seasonal cycles for the 201 and 213 kyr BP cases.

different interacting processes. However, the coupled GCM experiments reported here indicate that the underlying mechanism behind the equatorial seasonality in SST is basic: two past insolation forcings with nearly opposite seasonal cycles were used, resulting in nearly opposite seasonal cycle for the equatorial SST and other oceanic and atmospheric variables. Our results are in accordance with the previous results of Short et al. (1991) and Crowley et al. (1992). This indicates that the key player in equatorial seasonality is the seasonality of the insolation forcing, with the ocean mixed layer temperature simply responding with some phase lag that depends on its heat capacity. Other mechanisms (e.g., Philander et al. 1996; Li and Philander 1996, 1997) are likely to be needed to explain regional SST patterns and seasonality.

Several implications can be drawn from the coupled GCM experiments presented here. First, the different equatorial seasonality in SST and SSS, due to the different insolation forcing, may affect proxy records that are based on planktonic species that preferentially grow within some favored temperature and salinity ranges. If the timing of these favorable conditions changes, then these proxies may represent different seasons at different time slices (cf. Gildor and Ghil 2002; Ashkenazy and Tziperman 2006).

Second, our preliminary results indicate a different magnitude and frequency of El Niño events under the two different seasonal insolation scenarios considered here. This is expected, as El Niño is tightly linked to equatorial Pacific SST, surface currents, location and intensity of the ITCZ, and timing of SST (e.g., Tziperman et al. 1998, 1997; Galanti and Tziperman 2000; Galanti et al. 2002). El Niño events may affect global climate (e.g., Cane 1998) and thus are of great importance.

Third, the atmospheric surface winds do not change significantly as a result of the different insolation forcing; in addition, somewhat surprisingly, the Hadley circulation changes only moderately when using the different insolation forcing. The Hadley circulation is commonly believed to be affected by several factors, including the location and intensity of the ITCZ, the equator-to-pole temperature gradient, and convection over the equatorial ocean (Held and Hou 1980; Lindzen and Hou 1988; Hou and Lindzen 1992; Schneider 2006; Walker and Schneider 2006). Our results may contribute to the effort 
Indian Ocean $\left(60^{\circ} \mathrm{E}\right)$

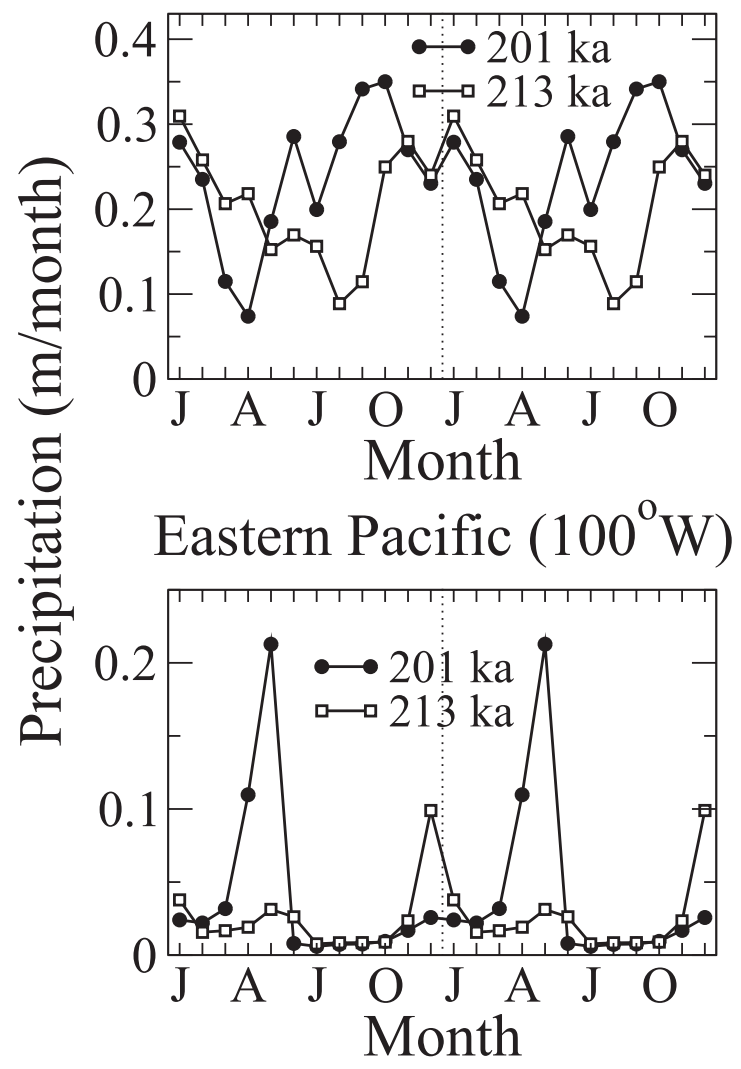

Western Pacific $\left(150^{\circ} \mathrm{E}\right)$

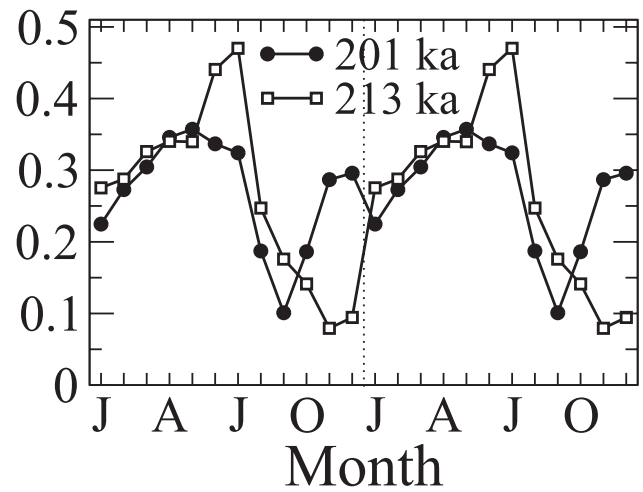

Atlantic Ocean $\left(30^{\circ} \mathrm{W}\right)$

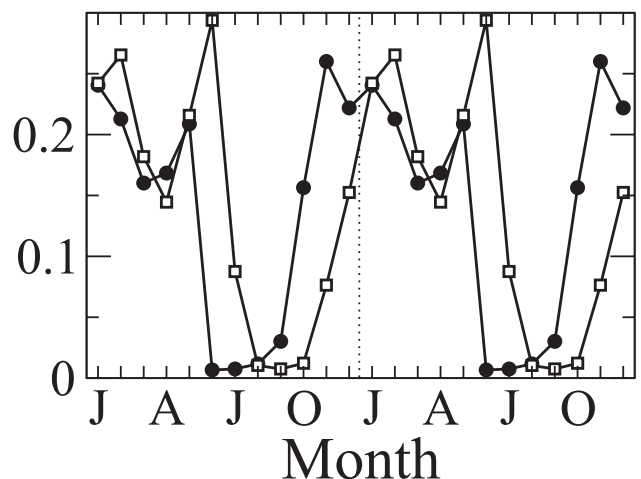

FIG. 8. As in Fig. 3, but for precipitation.

to understand which factor is the main controlling factor of the Hadley cell amplitude, given that we see very small changes to the Hadley cell despite significant changes to the equatorial SST and the location of the ITCZ.

Acknowledgments. We thank the United States-Israel Binational Science Foundation for its financial support. Author IE is funded by a Prize Postdoctoral Fellowship through Caltech's Division of Geological and Planetary Sciences and a NOAA Climate and Global Change Postdoctoral Fellowship administered by the University Corporation for Atmospheric Research; ET is funded by the NSF P2C2 program through Grant ATM-0902844.

\section{REFERENCES}

Ashkenazy, Y., and E. Tziperman, 2006: Scenarios regarding the lead of equatorial sea surface temperature over global ice volume. Paleoceanography, 21, PA2006, doi:10.1029/2005PA001232.

__ and H. Gildor, 2008: Timing and significance of maximum and minimum equatorial insolation. Paleoceanography, 23, PA1206, doi:10.1029/2007PA001436.

Berger, A., 1978: Long-term variations of daily insolation and quaternary climate changes. J. Atmos. Sci., 35, 2362-2367.
— M. F. Loutre, and J. L. Mélice, 2006: Equatorial insolation: From precession harmonics to eccentricity frequencies. Climate Past, 2, 131-136.

Cane, M. A., 1998: Climate change: A role for the tropical Pacific. Science, 282, 59-61.

Chang, P., 1996: The role of the dynamic ocean-atmosphere interactions in the tropical seasonal cycle. J. Climate, 9, 2973-2985.

Clement, A. C., R. Seager, and M. A. Cane, 1999: Orbital controls on the El Niño/Southern Oscillation and the tropical climate. Paleoceanography, 14, 441-456.

Collins, W. D., and Coauthors, 2006: The Community Climate System Model version 3 (CCSM3). J. Climate, 19, 2122-2143.

Crowley, T. J., K.-Y. Kim, J. G. Mengel, and D. A. Short, 1992: Modeling 100,000-year climate fluctuations in pre-Pleistocene time series. Science, 255, 705-707.

Dima, I. M., and J. M. Wallace, 2003: On the seasonality of the Hadley cell. J. Atmos. Sci., 60, 1522-1527.

Galanti, E., and E. Tziperman, 2000: ENSO's phase locking to the seasonal cycle in the fast SST, fast wave, and mixed mode regimes. J. Atmos. Sci., 57, 2936-2950.

,$- \ldots$, M. Harrison, A. Rosati, R. Giering, and Z. Sirkes, 2002: The equatorial thermocline outcropping-A seasonal control on the tropical Pacific ocean-atmosphere instability strength. J. Climate, 15, 2721-2739.

Gildor, H., and M. Ghil, 2002: Phase relations between climate proxy records: Potential effect of seasonal precipitation changes. Geophys. Res. Lett., 29, 1024, doi:10.1029/2001GL013781. 
Gu, D., S. G. H. Philander, and M. J. McPhaden, 1997: The seasonal cycle and its modulation in the eastern tropical Pacific Ocean. J. Phys. Oceanogr., 27, 2209-2218.

Held, I. M., and A. Y. Hou, 1980: Nonlinear axially symmetric circulations in a nearly inviscid atmosphere. J. Atmos. Sci., 37, 515-533.

Horel, J. D., 1982: On the annual cycle of the tropical Pacific atmosphere and ocean. Mon. Wea. Rev., 110, 1863-1878.

Hou, A. Y., and R. S. Lindzen, 1992: The influence of concentrated heating on the Hadley circulation. J. Atmos. Sci., 49, 12331241.

Huybers, P., and P. Molnar, 2007: Tropical cooling and the onset of North American glaciation. Climate Past, 3, 549-557.

Köberle, C., and S. G. H. Philander, 1994: On the processes that control seasonal variations of sea surface temperatures in the tropical Pacific ocean. Tellus, 46A, 481-496.

Kukla, G., and J. Gavin, 2004: Milankovitch climate reinforcements. Global Planet. Change, 40, 27-48.

$\longrightarrow$, and — 2005: Did glacials start with global warming? Quat. Sci. Rev., 24, 1547-1557.

Laskar, J., 1990: The chaotic motion of the solar system: A numerical estimate of the chaotic zones. Icarus, 88, 266-291.

— , F. Joutel, and F. Boudin, 1993: Orbital, precessional, and insolation quantities for the earth from -20 myr to +10 myr. Astron. Astrophys., 270, 522-533.

Li, T., and S. G. H. Philander, 1996: On the annual cycle of the eastern equatorial Pacific. J. Climate, 9, 2986-2998.

$\longrightarrow$, and - 1997: On the seasonal cycle of the equatorial Atlantic Ocean. J. Climate, 10, 813-817.

Lindzen, R. S., and A. Y. Hou, 1988: Hadley circulations for zonally averaged heating centered off the equator. J. Atmos. Sci., 45, 2416-2427.

Meehl, G. A., and Coauthors, 2006: Climate change projections for the twenty-first century and climate change commitment in the CCSM3. J. Climate, 19, 2597-2616.

Milankovitch, M., 1941: Canon of Insolation and the Ice-Age Problem (in German). Special Publications of the Royal Serbian Academy, Vol. 132, Israel Program for Scientific Translations, $484 \mathrm{pp}$.

Mitchell, T. P., and J. M. Wallace, 1992: The annual cycle in equatorial convection and sea surface temperature. J. Climate, 5, $1140-1156$.
Nigam, S., and Y. Chao, 1996: Evolution dynamics of tropical oceanatmosphere annual cycle variability. J. Climate, 9, 3187-3205.

Otto-Bliesner, B. L., and A. Clement, 2005: The sensitivity of the Hadley circulation to past and future forcings in two climate models. The Hadley Circulation: Present, Past, and Future, H. F. Diaz and S. Raymond, Eds., Advances in Global Change Research, Vol. 21, Springer, 437-464.

_, E. C. Brady, G. Clauzet, R. Tomas, S. Levis, and Z. Kothavala, 2006: Last Glacial Maximum and Holocene climate in CCSM3 J. Climate, 19, 2526-2544.

Paillard, D., 2001: Glacial cycles: Toward a new paradigm. Rev. Geophys., 39, 325-346.

Philander, S. G. H., W. J. Hurlin, and A. D. Siegel, 1987: Simulation of the seasonal cycle of the tropical Pacific Ocean. J. Phys. Oceanogr., 17, 1986-2002.

- D. Gu, D. Halpern, G. Lambert, N.-C. Lau, T. Li, and R. C. Pacanowski, 1996: Why the ITCZ is mostly north of the equator. J. Climate, 9, 2958-2972.

Sachs, J. P., R. H. Sachse, D. Smittenberg, Z. Zhang, D. S. Battisti, and S. Golubic, 2009: Southward movement of the Pacific intertropical convergence zone AD 1400-1850. Nat. Geosci., 2, 519-525.

Schneider, T., 2006: The general circulation of the atmosphere. Annu. Rev. Earth Planet. Sci., 34, 655-688, doi:10.1146/ annurev.earth.34.031405.125144.

Short, D. A., J. G. Mengel, T. J. Crowley, W. T. Hyde, and G. R. North, 1991: Filtering of Milankovitch cycles by Earth's geography. Quat. Res., 35, 157-173.

Tziperman, E., L. Stone, M. A. Cane, and H. Jarosh, 1994: El Niño chaos: Overlapping of resonances between the seasonal cycle and the Pacific ocean-atmosphere oscillator. Science, 264, 72-74. -, S. E. Zebiak, and M. A. Cane, 1997: Mechanisms of seasonal ENSO interaction. J. Atmos. Sci., 54, 61-71.

_, M. A. Cane, S. E. Zebiak, Y. Xue, and B. Blumenthal, 1998: Locking of El Niño's peak time to the end of the calendar year in the delayed oscillator picture of ENSO. J. Climate, 11, 2191-2199.

Walker, C. C., and T. Schneider, 2006: Eddy influences on Hadley circulations: Simulations with an idealized GCM. J. Atmos. Sci., 63, 3333-3350.

Wang, B., and Y. Wang, 1999: Dynamics of the ITCZ-equatorial cold tongue complex and causes of the latitudinal climate asymmetry. J. Climate, 12, 1830-1847. 